\title{
FORECASTING AND INVENTORY PERFORMANCE IN DIRECT- STORE DELIVERY SUPPLY CHAIN: CASE OF RETAILER IN SERBIA
}

\author{
Milan Dobrota ${ }^{1}$, Mirko Vujošević ${ }^{2}$ \\ ${ }^{1,2}$ University of Belgrade, Faculty of Organizational Sciences, Jove Ilića 154, 11000 Belgrade, Serbia
}

Received 9 November 2014; accepted 23 December 2014

\begin{abstract}
This paper presents research conducted on the case of food retailer in Serbia in order to answer at which level are the forecasting techniques applicable to such companies, at given supply chain model and in given environment. We will validate the usability of TrendSeasonality-Corrected Exponential Smoothing (Winter's Model) as a model that can improve inventory management in such case.
\end{abstract}

Keywords: forecasting, supply chain, inventory performance.

\section{Introduction}

The customer demand is at the very beginning of planning process in supply chain (Diabat, 2014; Lorentziadis, 2014), thus forecasting the supply chain is crucial for any optimization process. Although authors focus generally on quantitative forecasting methods (Chopra and Meindl, 2007), companies must balance objective and subjective factors when forecasting user demands, meaning they also must include human input when they make their final forecast. To achieve so, a company must be knowledgeable about numerous factors that are related to the forecast demands, such as: past demand, lead time of product, planned advertising or marketing efforts, state of the economy, planned price discounts and actions that competitors have taken. Generally, according to Chopra and Meindl (2007) forecasting methods are classified by the following four types: Qualitative, Time series, Causal and Simulation. In this paper we focus on Time series forecasting, which is one of the most important quantitative models in which historical observations of the same variable are collected and analyzed to develop a model that captures the underlying data generating process (Kuremoto et al., 2014; Jin et al., 2014). This modeling approach is particularly useful when little knowledge is available on the data generating process or when there is no satisfactory explanatory model that relates the prediction variable to other explanatory variables (Khashei and Bijari, 2012).

Purpose of this research paper is not to discuss and find better ways to forecast, but to discuss its applicability, validity and usability in practice, given particular case. This particular case is a retailer that operates in Serbia. We will evaluate real data in order to test and validate used forecasting model, which is Trend-Seasonality-

\footnotetext{
${ }^{2}$ Corresponding author: mirkov@fon.bg.ac.rs
} 
Corrected Exponential Smoothing (Winter's Model). Considering the practical side of this paper, it is important to show that the model discussed "works in practice", for particular business case.

\subsection{Case of Retailer in Serbia}

Company A is a food retailer that among other countries operates in Serbia. It operates chain of super-markets in most of the larger cities in Serbia. Considering the size of stores, each store disposes with storage space which is large enough to give options for inventory optimization. Being the food retailer, most of its inventory is fast moving, with generally predictable demand. By this fact, and by the fact that supermarkets are territorially dispersed, the management of the company assumed that it is unlikely that company can benefit from risk pooling and other benefits, so it does not dispose with DC (central warehouse). As a consequence, stores are supplied $100 \%$ by direct store deliveries from the supplier. Focusing just to direct store delivery reduces the maneuver for optimization. However, the other food retailers in Serbia (authors of this paper being familiar with retail market in Serbia) which do have their own DCs, for most of the fast moving merchandise also use direct store deliveries from their suppliers. For example, company B, which has its own DC and many less territorially dispersed stores, still supply their stores with direct store delivery for about $70 \%$ of articles. This sustains the claim that there is a lot of room for improvements in how supply chains are managed in Serbia, so this article will try to contribute to how the food retailers optimize their inventory, with direct store delivery as supply method, being the most common one. Focusing on usability of techniques, we shall examine only one supermarket (located in Belgrade), thus only demand of one single store, although aggregate forecasts are usually more accurate than disaggregate forecasts, as they tend to have a smaller standard deviation of error relative to the mean (Chopra and Meindl, 2007). In other words, if model can work for one single store, we can assume it will perform even better when multiple stores are aggregated.

In Store 1, retailer A orders its inventory to the supplier manually, by entering order in the ERP system based on the proposal given in form of the report. Manual entry has the advantage of still giving the opportunity to buyer to correct the order due to the elements that cannot be calculated by the system (such as weather), but brings the higher costs of order placement and it is more likely that the elements that could be calculated will not be taken into account, or will be calculated wrongly, especially since we deal with large number of orders and articles on daily basis. Orders are placed by Periodic review replenishment policy (generally with period $\mathrm{T}=1$ week, which means that the inventory is examined on weekly basis) and proposed lot size $Q$ to order is calculated in following way:

$Q_{t}=\frac{\left(D_{t-4}+D_{t-3}+D_{t-2}+D_{t-1}\right)}{28} \cdot N-S O H$

where $Q_{t}$ is quantity to order in week $t, D_{n}$ is demand (quantity sold) in week $n, N$ is number of days which is Target Stock Rotation, and it represents the number of days "the ordered stock should cover the demand", and it bases on rule of the thumb rather than any calculation which involves some optimization technique. It is determined for the department or section of products in the hierarchy (e.g. non-alcoholic drinks) and not per-article. Finally, $\mathrm{SOH}$ is Stock 
On Hand, which is quantity on stock in the moment of ordering. Basically this is a Moving Average model, which uses last 4 weeks of sales to calculate average daily sales and then it multiplies it with number of days for which we wish to have the stock for such fixed demand. Existing stock is then reduced from quantity to order. This model has number of disadvantages:

- Forecasting model downsides:

- Does not include trends (demand in week $t$ is assumed not to grow comparing to last 4 weeks)

- Does not include seasons (demand in week $t$ is assumed to have same seasonality as last 4 weeks)

- Other downsides:

- $\quad \mathrm{N}$ is determined per department, not per article (all articles of department are treated as "movers" of same speed)

- $\quad \mathrm{N}$ is not calculated based on EOQ (Economic Order Quantity), with optimal ordering lot size, nor based on optimal Safety Stock for given Cycle Service Level

- Does not include lead time of delivery in the model to calculate safety stock

So, due to bad forecasting and other elements discussed above, company $\mathrm{A}$ is forced to put enough safety with $\mathrm{N}$ being large enough. If $N>$ ordering periodicity, quantity to order will be corrected with $\mathrm{SOH}$, but as a consequence constant overstock is possible (ordering lot small due to large $\mathrm{SOH}$ ). E.g. although Periodic review replenishment policy is conducted by weekly examination of stock, all article except fresh (supplied daily) are set with $N$ between 7 and 21, although lead time for deliveries is generally next-daydelivery or few days.

\section{Research Methodology}

According to Chopra and Meindl (2007) the following basic, six-step approach is needed to perform effective forecasting. Understand the objective of forecasting: here, our objective is to do a "proof of concept" that even the relatively simple forecasting technique, for the low level of demand aggregation and in direct-store delivery supply chain (being the most widely spread in Serbia), can be of great value for managing the inventory. Integrate demand planning and forecasting throughout the supply chain: also for the purpose of this research, we will ignore the benefits that are to be achieved if the results of forecasting are integrated and shared upstream the supply chain. However, it is important to stress out that the real benefits in optimizing inventory in direct-store delivery supply chain can be achieved only with the proper cooperation with suppliers, which assumes the mentioned information sharing. Understand and identify customer segments: we will not be dealing here with this aspect, since we are forecasting demand for the general merchandise (common goods) by the general population. Identify the major factors that influence the demand forecast: here we shall focus only on calculative quantitative factors of time series, as described in model below. We will not be dealing with any qualitative, causal of speculative elements. Determine the appropriate forecasting technique: we will use mixed ((level + trend) x seasonal factor) Trend-Seasonality-Corrected Exponential Smoothing (Winter's Model), which will be compared to Moving Average. This technique was chosen for "proof of concept" purpose because it is not complex while it includes, beside a level, also trend and seasonality elements. Establish performance and error measures for the forecast: we will use 
common measures such as: MSE (Mean Squared Error), MAD (Mean Average Deviation), MAPE (Mean Absolute Percentage Error), Bias, and TS (Tracking Signal).

\subsection{Data}

Data for analysis is obtained from the transactional ERP system of the company A. First it was necessary to get the representative articles (SKUs) which will make a good example for research. For this purpose we've chosen product Family and then Sub-family in the classification in such way that they contained products of different nature: with more or less seasonality, faster and slower moving, etc. First we pre-selected 3 Families as given in Table 1, and 5 Sub-families to look articles in. Then we checked one month of sales to find either the articles with most sales, or articles with less sales but higher price (which have significant impact on inventory holding costs because of their value). We've also checked the number of orders/receptions in that period, not to catch the extreme cases. We ended up with the following articles as given in Table 1.

\section{Table 1}

Families, Sub-Families and Articles Analyzed

\begin{tabular}{|l|l|l|}
\hline \multirow{2}{*}{ Family } & Sub-Family & Article \\
\hline \multirow{2}{*}{$\begin{array}{l}\text { FROZEN PRODUCTS } \\
\text { ANCECREAMS }\end{array}$} & ICECREAMS AND ICE DAINTY & QUATTRO CHOCO FANTASY \\
\cline { 2 - 3 } & $\begin{array}{l}\text { FROZEN FRUITS AND } \\
\text { VEGETABLES }\end{array}$ & VULKANO ČOKOLADA-VANILA 500ML \\
\cline { 2 - 3 } $\begin{array}{l}\text { UNALCOHOLIC } \\
\text { BEWERAGE }\end{array}$ & WATERS & FRIKOM POVRĆE RUSKA 450 \\
\hline \multirow{2}{*}{$\begin{array}{l}\text { WINES AND } \\
\text { ALCOHOLIC }\end{array}$} & BEWERAGE & MINERALNA VODA 2L MINAKVA \\
\cline { 2 - 3 } & \multirow{2}{*}{\begin{tabular}{l} 
WINES \\
\cline { 2 - 3 }
\end{tabular}} & JELEN PIVO 0.5L POVRATNA \\
\cline { 2 - 3 } & & PIVO LAV 0.5L POVRATNA \\
\cline { 2 - 3 } & & VRANAC ŽUPA 1L \\
\hline
\end{tabular}

Here we will present the calculation in more details with one article, carbonated mineral water "KNJAZ MILOŠ $1.5 \mathrm{~L}$ PET GAZIRANA", but at the end we will check the calculated data for each article. Next step is extraction of weekly statistics for each article. Data extracted for each week is: sales, quantity ordered, quantity received and average quantity on stock (average quantity at the end of each day of the week), but for purpose of this research we will use only sold quantity data. Also, monthly statistics data was extracted to compare the analysis vs. weekly, but clearly weekly analysis is more accurate, mostly because: weekly seasonality is more precise than monthly, and most of the supply is done on weekly basis, so weekly forecasting gives greater opportunity for optimization. Extracted and analyzed data is from Week 1 of 2010 to Week 25 of 2014. Weeks with 0 sales (which happens if article was not active in period or if it is slow moving article) are replaced with sales of 1 piece, so that we can also test the models in this case and being able to calculate forecasting errors relative to demand. 
For one article we easily observed how, for example in 2012, average weekly sales was 388 SKUs, while average stock was 1185 , which means that average stock covers 3.05 weeks of sales. We can also observe that replenishment is done irregularly but in average every 1.63 weeks. This clearly indicates that there is a significant room for reduction of inventory costs.

\subsection{Model}

First step is to conduct static forecasting method in order to be able to extract Systematic component of the forecast, which is (given the mixed form of calculating it): Systematic component $=($ level + trend $) \mathrm{x}$ seasonal factor (Chopra and Meindl, 2007). This means that we need to estimate the level, the trend, and the seasonal factor. The second step is to run given Exponential smoothing algorithm. Further we describe the forecast model as explained in (Chopra and Meindl, 2007), where the steps are:

- Initialize: deseasonalize demand, estimate level and trend (run linear regression), estimate seasonal factors,

- Apply algorithm (Winter's Model): forecast, estimate error, modify estimates and repeat forecast,

- Calculate measures of forecast error.

We will validate the forecasting model by comparing measures of forecasting errors between current ordering model and Winter's model. We will use following measures:

- Mean Squared Error (MSE). The MSE can be related to the variance of the forecast error. We estimate that the random component of demand has a mean of 0 and variance of MSE.

- Mean Absolute Deviation (MAD) is average of the absolute deviation (the absolute value of the error in Period $t$ ) over all periods. The MAD can be used to estimate the standard deviation of the random component assuming that the random component is normally distributed. In this case the standard deviation of the random component is $\sigma=1.25 \mathrm{MAD}$.

- Mean Absolute Percentage Error (MAPE) is the average absolute error as a percentage of demand.

- Bias: to determine whether a forecast method consistently over- or underestimates demand, we can use the sum of forecast errors to evaluate the bias. The bias will fluctuate around 0 if the error is truly random and not biased one way or the other.

- Tracking Signal (TS) is the ratio of the bias and the MAD. If the TS at any period is outside the range \pm 6 , this is a signal that the forecast is biased and is either under forecasting $(T S<-6)$ or over forecasting $(T S>+6)$.

Additionally, in this paper we introduce calculation of optimal parameters of Winter's Model, $a, \beta$, and $\gamma$, as the final step for analysis. Parameters $\alpha, \beta$ and $\gamma$ can vary in range $0 . . .1$ and thus affect the smoothing of the forecast calculation. We could assume that the parameters should be such that they minimize the measures of forecast errors, such as MAD, MAPE, Bias and TS. After some quick empirical testing, we adopted that an option to calculate the parameters is by using one of two following optimization:

$$
\begin{aligned}
& \min f(\alpha, \beta, \gamma)=M A D \\
& \min f(\alpha, \beta, \gamma)=\left(\sum_{t=1}^{n} A_{t}\right) \cdot\left(\sum_{t=1}^{n}\left|T S_{t}\right|\right)
\end{aligned}
$$


Subject to: $0 \leq \alpha \leq 1,0 \leq \beta \leq 1$ and $0 \leq \gamma \leq 1$. In this way we try to minimize either MAD, thus we give more importance to the variance and deviation or TS, thus the Bias.

This calculation can be done using Microsoft Excel and its Solver add-in. This is definitely the subject that can be suitable for further analysis: optimization of these parameters.

\subsection{Results}

Applying the calculations from the model to article (SKU) carbonated mineral water "KNJAZ MILOŠ 1.5L PET GAZIRANA", for $\alpha=0.5, \beta=0.05$ and $\gamma=0.05$, we calculate the forecasts as displayed in Fig. 1. It displays real sales, forecasting achieved by Winter's Model and forecasting as currently used by company A.

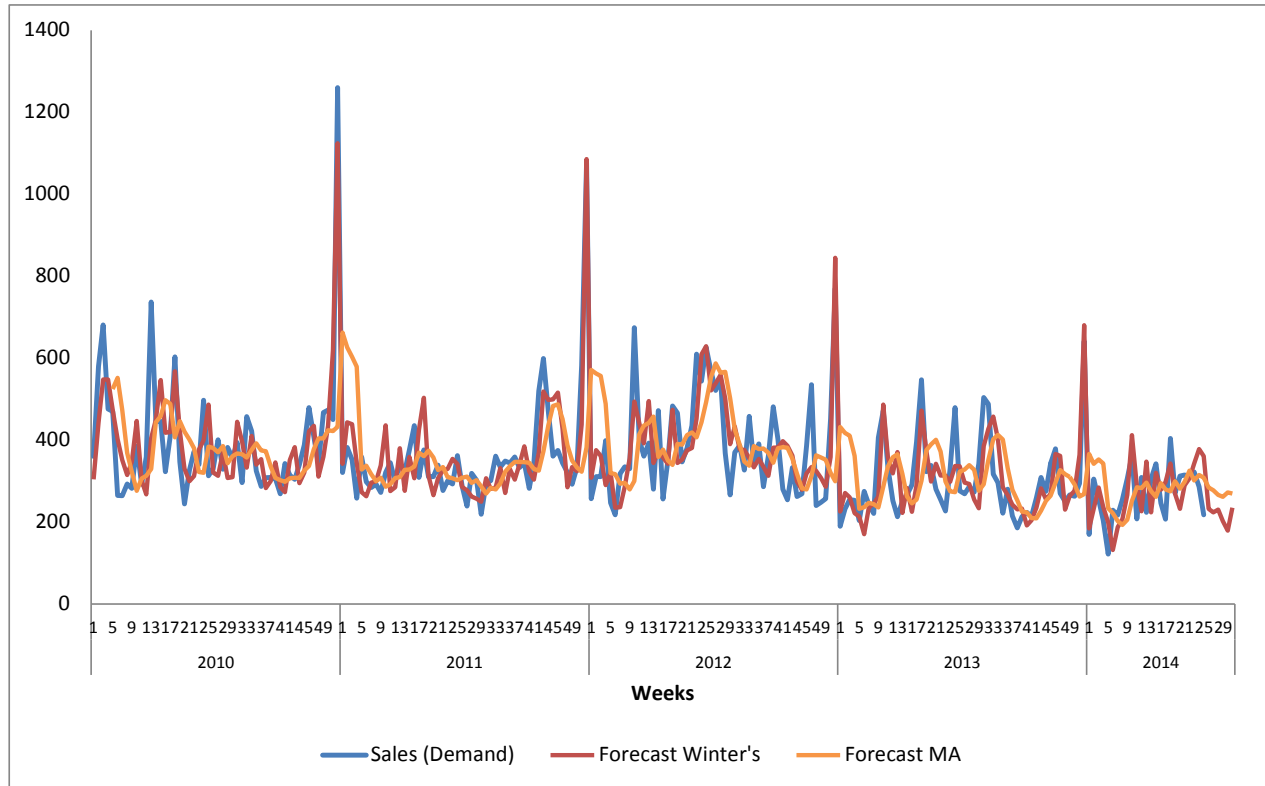

Fig. 1.

Winter's Model and MA Forecast Compared to Sales

Table 2 summarizes results obtained in this research, where different forecast error measures are given for same article and data set, by using two forecasting models: existing model of company A, being moving average for 4 weeks, versus exponential smoothing with trend and season correction (Winter's model). 
Table 2

Comparison of Forecasting Errors for Models Used on Data Set

\begin{tabular}{|c|c|c|c|c|c|c|c|c|c|c|c|c|}
\hline \multirow[b]{2}{*}{ Article } & \multicolumn{6}{|c|}{ Moving Average Model } & \multicolumn{6}{|c|}{ Exponential Smoothing Winter's Model } \\
\hline & MSE & MAD & MAPE & $\Sigma$ Bias & $\begin{array}{l}\text { TS off } \\
\text { range }\end{array}$ & $\sigma$ & MSE & MAD & MAPE & $\Sigma$ Bias & $\begin{array}{l}\text { TS off } \\
\text { range }\end{array}$ & $\sigma$ \\
\hline $\begin{array}{l}\text { QUATTRO CHOCO } \\
\text { FANTASY }\end{array}$ & 433 & 6 & 103 & -3348 & 233 & 7 & 615 & 5 & 85 & 456 & 171 & 7 \\
\hline $\begin{array}{l}\text { VULKANO } \\
\text { ČOKOLADA-VANILA } \\
\text { 500ML }\end{array}$ & 215 & 5 & 66 & -3799 & 51 & 6 & 264 & 7 & 102 & 1006 & 36 & 9 \\
\hline $\begin{array}{l}\text { FRIKOM ĐUVEĆ } \\
450 \mathrm{GR}\end{array}$ & 763 & 15 & 54 & 5590 & 24 & 19 & 368 & 11 & 41 & 11755 & 79 & 14 \\
\hline $\begin{array}{l}\text { FRIKOM POVRĆE } \\
\text { RUSKA } 450\end{array}$ & 2988 & 27 & 66 & 17592 & 43 & 34 & 788 & 15 & 39 & -319 & 12 & 19 \\
\hline $\begin{array}{l}\text { KNJAZ MILOŠ 1.5L } \\
\text { PET GAZIRANA }\end{array}$ & 18710 & 90 & 26 & 112888 & 108 & 112 & 5668 & 59 & 18 & -3759 & 0 & 74 \\
\hline $\begin{array}{l}\text { MINERALNA VODA } \\
\text { 2L MINAKVA }\end{array}$ & 41969 & 129 & 19 & 164219 & 106 & 161 & 61721 & 129 & 18 & -66829 & 1 & 161 \\
\hline $\begin{array}{l}\text { JELEN PIVO 0.5L } \\
\text { POVRATNA }\end{array}$ & 115808 & 192 & 646 & 91250 & 40 & 240 & 75642 & 164 & 64 & -87116 & 30 & 206 \\
\hline $\begin{array}{l}\text { PIVO LAV 0.5L } \\
\text { POVRATNA } \\
\end{array}$ & 25282 & 84 & 819 & 113786 & 81 & 105 & 9469 & 68 & 298 & -86564 & 51 & 86 \\
\hline VRANAC ŽUPA 1L & 518 & 13 & 230 & 19958 & 136 & 17 & 675 & 12 & 180 & 19699 & 124 & 16 \\
\hline VRANAC 1L & 90 & 6 & 66 & 17944 & 192 & 8 & 38 & 5 & 46 & 8545 & 129 & 6 \\
\hline
\end{tabular}

\subsection{Analysis}

Although not displayed here, value of $a$ parameter calculated by solver was very high. It can indicate either that the selected forecasting model is not the most suitable one or that optimization of this parameter needs more adjustment. However, it anyway performs significantly better than the existing moving average technique. Parameter $\beta$ was lower comparing to $\alpha$ which means that trend is kept much more constant and should be taken more into consideration. Parameter $\gamma$ was also relatively high, though much lower than $a$. This means that there is a moderate change of seasonality factors over time. However, selection of these parameters was quite quick and empirical, using solver to minimize forecasting error measures. Further work should probably pay more attention to definition and analysis of these parameters and how to optimize forecasting models when using exponential smoothing in this regard.
Based on results shown in Table 2 we can easily conclude how Winter's model gives better results comparing to simple moving average used in company A. However, we can observe how it performs better for higher levels of demand aggregation (meaning for articles with higher demand levels), which sustains the claim (Chopra and Meindl, 2007) how demand forecasting performs better when level of aggregation is higher. This means that if we would observe cluster of stores, rather than one single, our forecasting would perform even better. Aside MSE, all other error measures are underperforming in Winter's model comparing to MA in just single case. In this analysis we paid special attention to Bias of forecasting and Tracking Signal. This because many TS out of given range are indicating that the forecasting model is probably not the most suitable one. Since Winter's model also performs significantly better in this regard, we can also conclude that it is more 
suitable than MA. We can conclude that Winter's exponential smoothing technique is usable to be implemented into replenishment process of company A and their directstore delivery supply chain. Retailer A uses Periodic replenishment policy, where in most cases stock is checked and orders are placed on weekly basis. It has agreed lead times for deliveries at the range from next day, to next business day, to few days or one week at most, but it stills experiences significant overstock. The company A could revise its replenishment policy and replace the model given by Eq. (1), to base on somewhat improved forecasting (such as one analyzed in this paper).

\section{Conclusion}

The objective of this paper was to validate the assumption that forecasting of direct-store delivery supply chain can be improved by changing to somewhat advanced forecasting technique. Based on applied research methodology and obtained results, such assumption can be confirmed. However, the forecasting technique used here is relatively simple and there are many ways to improve it for particular case, which is left here for further research.

For example, here we were dealing with the demand on weekly level. However, orders can be placed on Monday or on Friday, which makes a significant turbulence in the model because we must account to 4 days of stock levels, lead times, etc. Therefore, model could be improved by assigning coefficients to each days of the week (e.g. on Saturdays and Sundays demand is significantly higher than on Monday). Furthermore, we should account on special weeks in the model. For example, Easter does not fall into same week each year, but it significantly disturbs the demand, and it is similar with other holidays, with days from $53^{\text {rd }}$ week (which is normally added to $52^{\text {nd }}$ ), etc. Also, regardless of any improvements it is important to know in practice, implementation of forecasting technique requires, beside careful planning, also many practical observations after forecast technique is launched, and many adjustments and improvements in pilot period.

\section{References}

Chopra, S.; Meindl, P. 2007. Supply Chain Management: Strategy, Planning, and Operation. Upper Saddle River, New Jersey: Pearson Education, Inc.

Diabat, A. 2014. Hybrid algorithm for a vendor managed inventory system in a two-echelon supply chain, European Journal of Operational Research. DOI: http://dx.doi. org/10.1016/j.ejor.2014.02.061, 238(1): 114-121.

Jin, S.N.; Su, L.J.; Ullah, A. 2014. Robustify Financial Time Series Forecasting With Bagging, Econometric Reviews. DOI: http://dx.doi.org/10.1080/07474938.2 013.825142, 33(5-6): 575-605.

Khashei, M.; Bijari, M. 2012. A new class of hybrid models for time series forecasting, Expert Systems with Applications. DOI: http://dx.doi.org/10.1016/j. eswa.2011.09.157, 39(4): 4344-4357.

Kuremoto, T.; Kimura, S.; Kobayashi, K.; Obayashi, M. 2014. Time series forecasting using a deep belief network with restricted Boltzmann machines, Neurocomputing. DOI: http://dx.doi.org/10.1016/j.neucom.2013.03.047, 137: 47-56.

Lorentziadis, P.L. 2014. Pricing in a supply chain for auction bidding under information asymmetry, European Journal of Operational Research. DOI: http:// dx.doi.org/10.1016/j.ejor.2014.02.051, 237(3): 871-886. 